Article

\title{
Improved Response of ZnO Films for Pyroelectric Devices
}

\section{Chun-Ching Hsiao * and Shih-Yuan Yu}

Department of Mechanical Design Engineering, National Formosa University, No. 64, Wunhua Rd., Huwei Township, Yunlin County 632, Taiwan; E-Mail: Shih.Yuan.Y@gmail.com

* Author to whom correspondence should be addressed; E-Mail: cchsiao@nfu.edu.tw; Tel.: +886-5-6315-557; Fax: +886-5-6363-010.

Received: 24 September 2012; in revised form: 6 December 2012 / Accepted: 7 December 2012 / Published: 12 December 2012

\begin{abstract}
Increasing the temperature variation rate is a useful method for enhancing the response of pyroelectric devices. A three-dimensional $\mathrm{ZnO}$ film was fabricated by the aerosol deposition (AD) rapid process using the shadow mask method, which induces lateral temperature gradients on the sidewalls of the responsive element, thereby increasing the temperature variation rate. To enhance the quality of the film and reduce the concentration of defects, the film was further treated by laser annealing, and the integration of a comb-like top electrode enhanced the voltage response and reduced the response time of the resulting $\mathrm{ZnO}$ pyroelectric devices.
\end{abstract}

Keywords: zinc oxide; aerosol deposition; electrode; pyroelectricity

\section{Introduction}

Zinc oxide $(\mathrm{ZnO})$ is a distinctive material because it possesses such properties as semiconductivity (II-VI compound semiconductors), piezoelectricity and pyroelectricity without the poling process, and it also has a low cost, low toxicity and is environmentally friendly. Interesting properties, including a large band gap $(\sim 3.3 \mathrm{eV})$, high transmittance, excellent thermal stability and $\mathrm{n}$ or $\mathrm{p}$ conductivity, are other attributes of $\mathrm{ZnO}$ material. Wide band gap wurtzite phase $\mathrm{ZnO}$ has attracted attention due to its versatility in many applications, such as blue and ultraviolet light emitters, transparent conductors, solar cell windows, gas sensors, photovoltaic devices, pyroelectric sensors, surface acoustic wave (SAW) devices, film bulk acoustic resonators (FBARs), catalysis, optoelectronics and photo-electrochemical devices [1-3]. 
$\mathrm{ZnO}$ films have been synthesized by numerous methods, such as metal organic chemical vapor deposition, molecular beam epitaxy, magnetron sputtering, pulsed laser deposition, atomic layer deposition, spray pyrolysis, the filtered cathodic vacuum arc technique and the sol-gel process. The quality of $\mathrm{ZnO}$ films obtained by the above methods depends on the specific growth methods and conditions. Thus, the preferential orientation of $\mathrm{ZnO}$ films depends on the growth conditions. The most densely packed and thermodynamically favorable growth orientation in the $\mathrm{ZnO}$ wurtzite structure is one in which the c-axis is perpendicular to the substrate. $\mathrm{ZnO}$ films with the c-axis normal to the substrate are preferred in many applications, such as pyroelectric devices [4,5] and film bulk acoustic resonators [6].

The pyroelectricity of $\mathrm{ZnO}$ is attributable to non-centrosymmetrical crystals, and so it has a specific polar axis along the direction of spontaneous polarization [4,5]. When $\mathrm{ZnO}$ is subjected to temperature variations, its internal polarization will produce an electric field. Pyroelectric materials respond to changes in temperature, which cause internal strain and in turn result in an electrical charge on the material surface. Therefore, increasing the response of a $\mathrm{ZnO}$ pyroelectric sensor depends on increasing the temperature variation rate of the $\mathrm{ZnO}$ layer, adopting a $\mathrm{ZnO}$ film with a strongly preferred orientation towards the $\mathrm{C}$-axis and using a high-performance thermal-isolation structure. Moreover, a partially covered top electrode has been proven to result in a higher response than a fully covered electrode, because it allows the pyroelectric layer to make direct contact with the heat source, thus increasing the temperature variation rate [4]. To enhance the temperature variation rate in pyroelectric films, a three-dimensional pattern is etched on the responsive element of $\mathrm{LiTaO}_{3}$ with lateral temperature gradients induced on the sidewalls of the responsive element under homogeneous irradiation for improving the response of pyroelectric devices [7]. Recently, pyroelectric energy modules offer novel energy conversion technology by transforming waste heat into electricity, which converts the time-dependent temperature variations into electrical energy. Pyroelectric energy conversion devices require the thermal cycling of a pyroelectric element between a hot and a cold temperature source to produce electricity [8-11]. Using the concept of lateral temperature gradients induced on the sidewalls of the responsive element, etching the PZT material to produce deeper cavities and a smaller electrode width can effectively enhance the temperature variation rate in a thicker PZT material, but the PZT etchant with a low etching rate is unsuitable to dig the deeper cavities in the PZT sheet [12]. Furthermore, while trenching the PZT sheets to produce deeper trenches can effectively enhance the temperature variation rate in a thicker PZT pyroelectric cell as a result of the lateral temperature gradients induced by the trenched electrode [13]. Hence, a three-dimensional pattern on pyroelectric elements or layers is positive for ameliorating the temperature variation rate and enhancing the response of pyroelectric devices. Besides, the Olsen cycle enables the generation of significant electrical energy using the pyroelectric effect. The Olsen cycle consists of two isothermal and two isoelectric field processes in the displacement versus the electric field diagram. A dipping experiment is used to perform the Olsen cycle by a piston oscillating vertically and driving silicon oil back and forth between a heat source and a cold heat exchanger in a Teflon cylindrical chamber [10]. Moreover, a stamping experiment is also used to implement the Olsen cycle by alternatively placing a pyroelectric material for heat conduction with a cold and a hot source [8]. Therefore, the various heat transfers also affect the efficiency of the Olsen cycle. 
Aerosol deposition (AD) is a novel deposition method developed by Akedo et al. In this technique, ceramic films are prepared by ejecting an aerosol consisting of a mixture of ultra-fine ceramic particles and gas from the nozzle to the substrate without vaporization of materials. AD has become very attractive for the deposition of ceramic films at room temperature on several kinds of substrates, such as silicon, glass, plastic and metal. In $\mathrm{AD}$, individual sub-micrometer particles of the materials being deposited are mixed with a carrier gas in the aerosol chamber to generate an aerosol flow. The flow is ejected through a micro-orifice nozzle and deposited onto a substrate in the deposition chamber, which is vacuumed during the deposition. Particle velocities are controlled by the gas flow consumption and measured with a mass flow controller. Compared with the sputtering, screen-printing or sol-gel methods, AD provides many advantages for producing films in the range of $1 \sim 100 \mu \mathrm{m}$ thickness with a high deposition rate, low deposition temperature and low cost [14]. The AD method can achieve fine results with a three-dimensional patterning $[15,16]$ and fabricate a dense structure by a reduction in crystallite size by fracture or plastic deformation at room temperature [14,17].

Although $\mathrm{ZnO}$ films grown at a low temperature are available from the AD process, an annealing treatment is necessary to further improve its quality and modulate its properties. Annealing treatment is one of the most common methods for reducing the defects and improving the quality of as-grown thin films $[18,19]$. Laser annealing of thin films is a technique of rapid crystallization that has the benefits of area selectivity, rapid local heating, no high temperature bulk heating, minimal disturbance to the surrounding area and flexible management $[1,20]$. Hence, laser annealing was adopted to improve the $\mathrm{ZnO}$ film quality in the present study, as it allowed for additional processing on devices that could not be processed at elevated temperatures. Moreover, in contrast with the thermal annealing treatment, laser irradiation can effectively reduce the residual stress and grain size in $\mathrm{ZnO}$ film [20].

In the present study, the preparation of $\mathrm{ZnO}$ films by $\mathrm{AD}$ was investigated. Moreover, a three-dimensional $\mathrm{ZnO}$ film fabricated by an $\mathrm{AD}$ rapid process with the shadow mask method which induces lateral temperature gradients on the sidewalls of the responsive element, thereby increasing the temperature variation rate and improving the response of pyroelectric sensors was applied to fabricate pyroelectric devices. Laser annealing was used to further improve the $\mathrm{ZnO}$ film quality. Then, the crystalline phases and the morphology of the $\mathrm{ZnO}$ films were characterized by X-ray diffraction (XRD) and scanning electron microscopy (SEM), respectively.

\section{Materials and Methods}

\subsection{Preparation of $\mathrm{ZnO}$ Films}

Figure 1 shows the schematic diagram of the AD apparatus, which consisted of both an aerosol and a deposition chamber. The aerosol chamber generated the $\mathrm{ZnO}$ aerosol. The aerosol flow of $\mathrm{ZnO}$ powder was formed by a carrier gas (nitrogen) and a vibration system. The vibration system was used to mix the $\mathrm{ZnO}$ powder with the carrier gas. The aerodynamic filter in the aerosol chamber was used to discard the agglomerated particles. The deposition chamber, used to form the films, consisted of an $\mathrm{X}-\mathrm{Y}$ stage, a nozzle and a substrate holder with a heating system. This chamber was evacuated during the film deposition process by a rotary vacuum pump with a dust collection system. The fine $\mathrm{ZnO}$ powder flow in the aerosol chamber was delivered to the deposition chamber by a pressure difference 
between the aerosol and deposition chambers. The fine $\mathrm{ZnO}$ powder flowed through the nozzle, and then impacted and deposited on the substrate to form the $\mathrm{ZnO}$ film. Particle velocities were controlled by the gas flow consumption and measured with a mass flow controller.

Figure 1. Apparatus for aerosol deposition system.

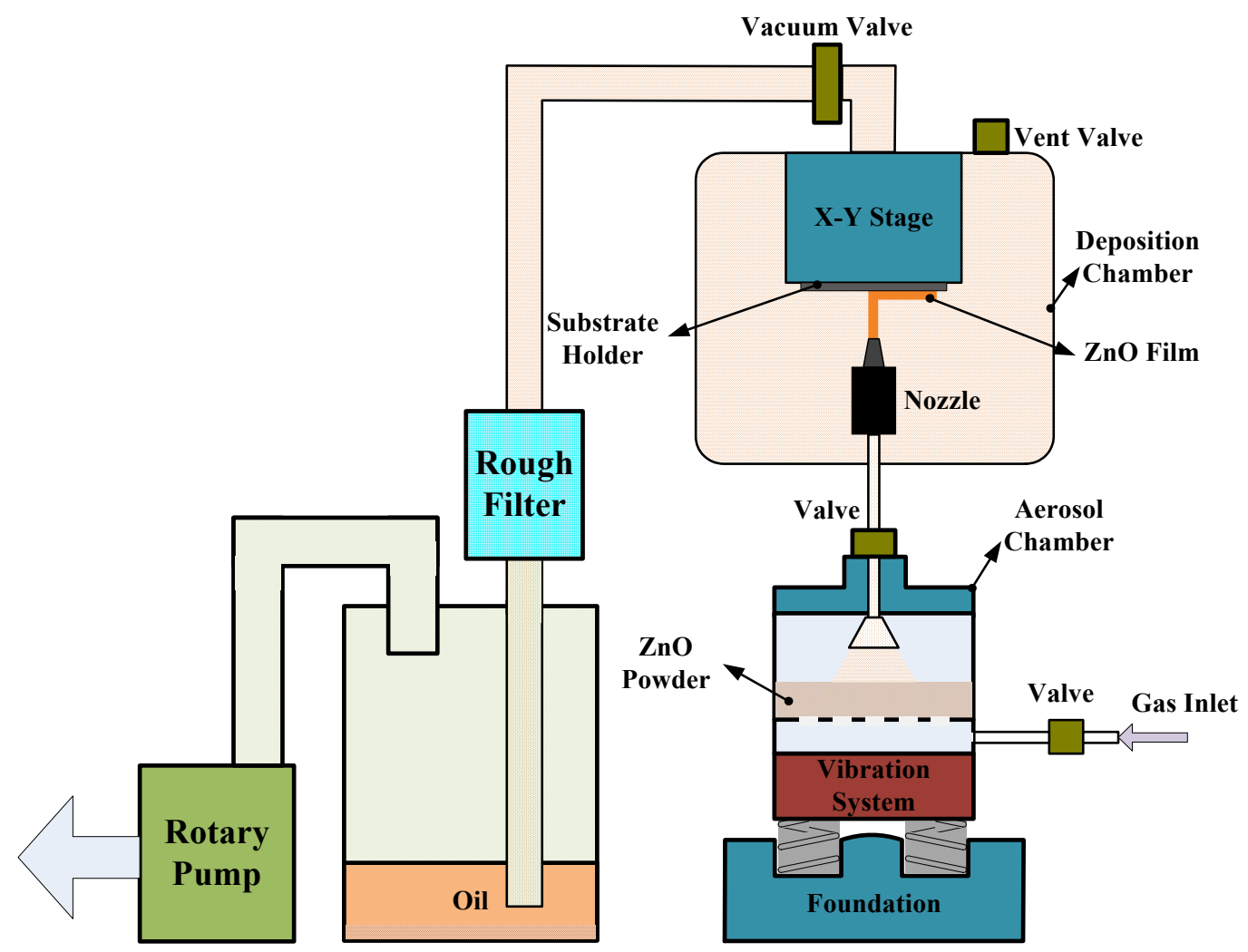

The starting powder was commercially available ZnO (Top Nano Technology Co. Ltd., New Taipei, Taiwan). The properties of the starting $\mathrm{ZnO}$ powder are shown in Table 1. Table 2 shows the deposition parameters used for the AD method. Starting powder with high moisture content reduces film quality, as agglomerated particles act as a cushion to absorb the kinetic energy, which results in the formation of compacted powders when the powder impacts against the substrate. Therefore, the pretreatment of the $\mathrm{ZnO}$ starting powder was carried out to improve the $\mathrm{ZnO}$ film quality. The powder was subjected to heat treatment at $150{ }^{\circ} \mathrm{C}$ for $1 \mathrm{~h}$ using an oven. $\mathrm{ZnO}$ film with a thickness of $3 \mu \mathrm{m}$ was deposited on the substrate, which consisted of $525 \mu \mathrm{m}$ thick silicon and $1 \mu \mathrm{m}$ thick silicon nitride, by $\mathrm{AD}$ at room temperature employing various process parameters. Then, laser annealing was applied to the $\mathrm{ZnO}$ films to enhance the film quality.

Table 1. Properties of $\mathrm{ZnO}$ powder.

\begin{tabular}{lc}
\hline \multicolumn{1}{c}{ Item } & Data \\
\hline Appearance & White powder \\
Density & $5.61 \mathrm{~g} / \mathrm{cm}^{3}$ \\
Specific surface area & $17 \mathrm{~m}^{2} / \mathrm{g}$ \\
Particle form & Sheet \\
Particle size & $300 \mathrm{~nm}$ (Diameter) $\times 20 \mathrm{~nm}$ (Thickness) \\
\hline
\end{tabular}


Table 2. Process parameters for $\mathrm{ZnO}$ film deposited by $\mathrm{AD}$ method.

\begin{tabular}{lc}
\hline \multicolumn{1}{c}{ Item } & Data \\
\hline Starting powder & $\mathrm{ZnO}$ \\
Substrate & Silicon \\
Pressure difference between & $140($ Torr $)$ \\
deposition and aerosol chambers & Nitrogen \\
Carrier gas & $3(\mathrm{~L} / \mathrm{min})$ \\
Consumption of carrier gas & $0.4 \times 10(\mathrm{~mm} \times \mathrm{mm})$ \\
Orifice size of nozzle & $25\left({ }^{\circ} \mathrm{C}\right)$ \\
Substrate temperature & $70 \times 70(\mathrm{~mm} \times \mathrm{mm})$ \\
Deposition area & $5(\mathrm{~mm})$ \\
Distance between nozzle and substrate & $10(\mathrm{~mm} / \mathrm{s})$ \\
Scanning rate & $8.2(\mathrm{~nm} / \mathrm{s})$ \\
Deposition rate &
\end{tabular}

The laser annealing system (LEE-25, Laser Life, Taipei, Taiwan), using continuous-wave $\mathrm{CO}_{2}$ laser irradiation with a wavelength of $10.6 \mu \mathrm{m}$, power of $25 \mathrm{~W}$ and beam diameter of $2 \mathrm{~mm}$, was adopted for the $\mathrm{ZnO}$ film annealing in a $\mathrm{N}_{2}$ atmosphere. The laser annealing parameters comprised the movement velocity of the laser head in the X-Y plane, distance between substrates and laser head, laser power adjustment, ambient gas and flow rate, as shown in Table 3.

Table 3. Process parameters for $\mathrm{ZnO}$ film treated by laser annealing.

\begin{tabular}{lc}
\hline \multicolumn{1}{c}{ Item } & Data \\
\hline Laser type & Continuous-wave $\mathrm{CO}_{2}$ laser \\
Laser power & $25(\mathrm{~W})$ \\
Movement velocity of laser head & $1.4(\mathrm{~mm} / \mathrm{s})$ \\
Distance between substrates and laser head & $40(\mathrm{~mm})$ \\
Ambient gas & Nitrogen \\
Flow rate of ambient gas & $3(\mathrm{~L} / \mathrm{min})$ \\
Laser spot & $2 \mathrm{~mm}$ (diameter) \\
\hline
\end{tabular}

The film thickness was measured by a surface analyzer (ET-4000AK, Kosaka, Tokyo, Japan). The crystalline phases of the $\mathrm{ZnO}$ films were identified by X-ray diffraction (XRD, PANalytical, X'Pert PRO MPD, Almelo, The Netherlands). The morphology was characterized by scanning electron microscopy (SEM).

\subsection{Structure and Fabrication of ZnO Thin-Film Pyroelectric Devices}

$\mathrm{ZnO}$ thin-film pyroelectric devices are comprised of a $\mathrm{ZnO}$ pyroelectric layer sandwiched between top and bottom electrodes and built on a thermal-isolation structure to block heat loss. The top side is exposed to a heat source. The principle of thin-film pyroelectric sensors is based on the pyroelectric effect, which converts the temperature variation to the corresponding electrical signal [4,5]. The dynamic pyroelectric response current of thin-film pyroelectric sensors can be described using Equation (1): 


$$
i_{p}=\eta \times P \times A \times d T / d t
$$

where $\eta$ is the absorption coefficient of radiation, $P$ is the pyroelectric coefficient of the pyroelectric film, $A$ is the sensing area and $d T / d t$ is the temperature variation rate of the pyroelectric film. The thermal-isolation structure, sensitive material properties, top-electrode layout and absorption coefficient are the most important performance-enhancing qualities of pyroelectric devices. From Equation (1), it can be seen that a higher temperature variation rate in pyroelectric films leads to a higher response current in the pyroelectric devices. Moreover, increasing the heat absorption of pyroelectric films can also improve the response of pyroelectric devices.

Figure 2. Schematic diagram of the multilayer $\mathrm{ZnO}$ pyroelectric device with the comb-like electrode and the three-dimensional $\mathrm{ZnO}$ film. (unit: $\mu \mathrm{m}$ ).
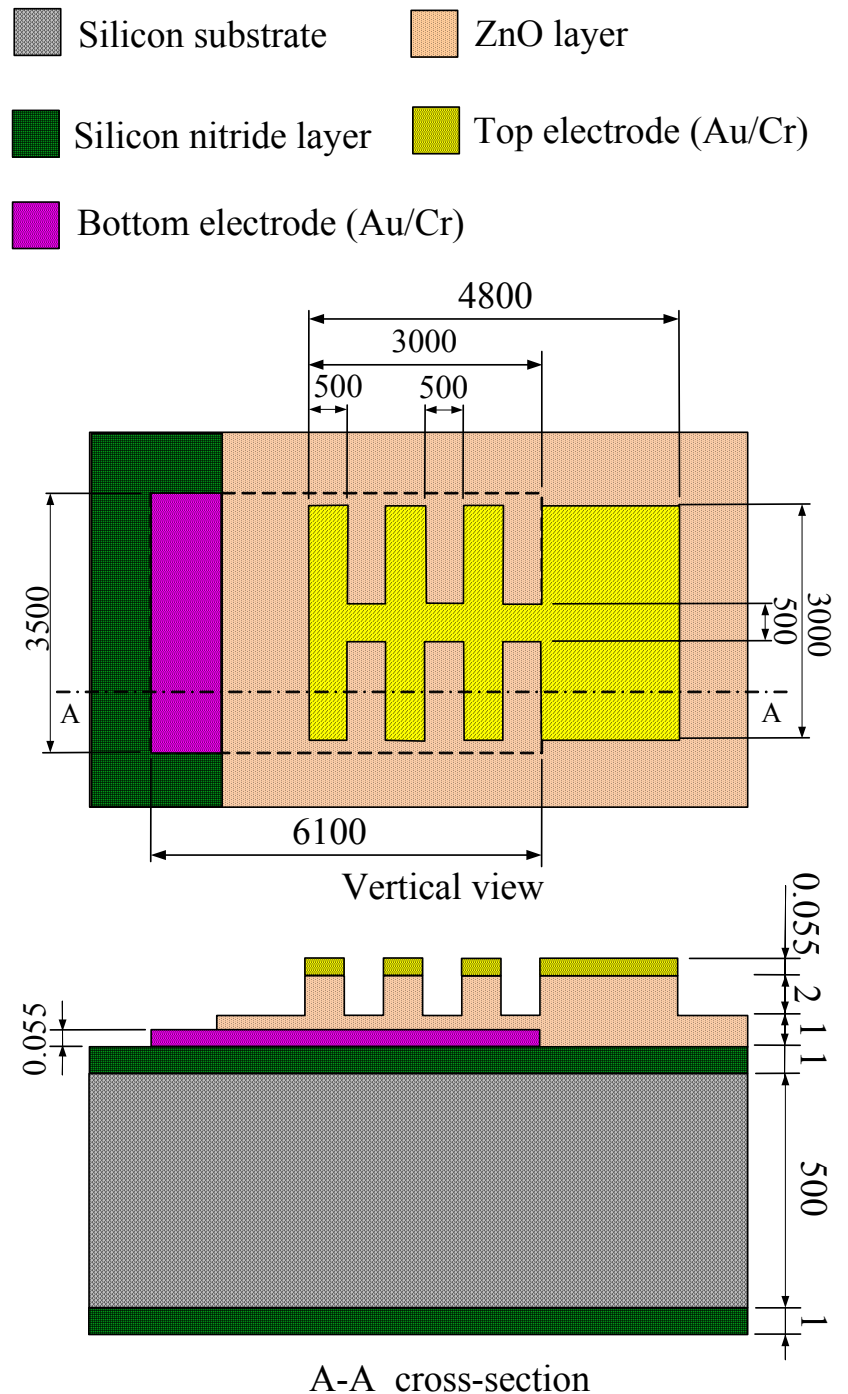

Temperature variation rates in pyroelectric layers seriously affect the response of pyroelectric sensors. A partially covered top electrode has a higher response than a fully covered top electrode because the uncovered part of the $\mathrm{ZnO}$ layer is directly exposed to the heat source and, thus, markedly increases the heat absorption [5]. Besides, a three-dimensional pattern in pyroelectric materials induces lateral temperature gradients on the sidewalls of the responsive element for increasing the temperature variation rate [7]. In the present study, the $\mathrm{AD}$ method was used to deposit a three-dimensional $\mathrm{ZnO}$ 
film integrated with a comb-like partially covered top electrode to enhance the performance of $\mathrm{ZnO}$ pyroelectric devices. The schematic diagram and dimensions of the pyroelectric device with the three-dimensional $\mathrm{ZnO}$ film and the comb-like electrode are detailed in Figure 2.

Figure 3. Process flow of the multilayer $\mathrm{ZnO}$ pyroelectric device with the comb-like electrode and the three-dimensional $\mathrm{ZnO}$ film.

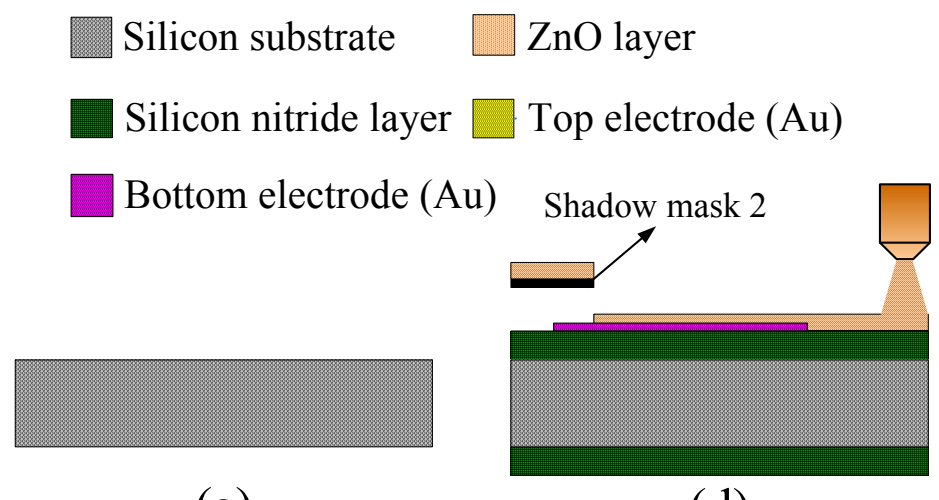

(a)

(d)

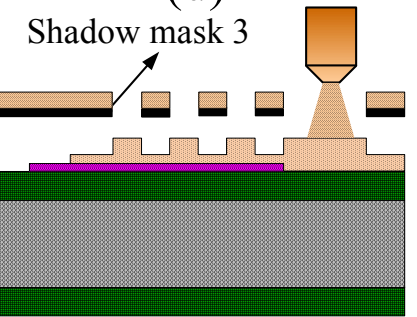

(b)

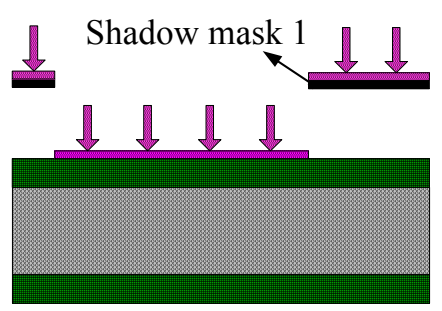

(c)

(e)

Nitrogen ambience

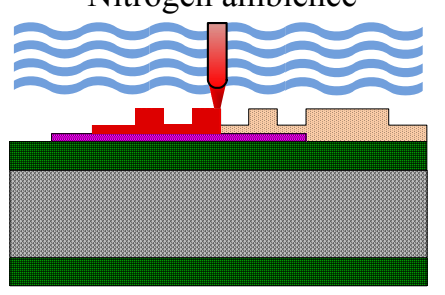

(f)

Shadow mask 3

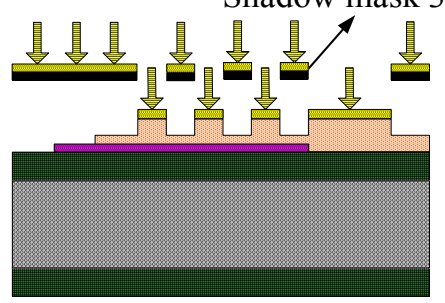

$(\mathrm{g})$

The fabrication flow of the $\mathrm{ZnO}$ pyroelectric devices was divided into several steps as follows: a silicon wafer with both sides polished was used as a substrate to support the multilayer $\mathrm{ZnO}$ pyroelectric devices, as shown in Figure 3(a). A $\mathrm{Si}_{3} \mathrm{~N}_{4}$ layer of $1 \mu \mathrm{m}$ thickness was deposited on both sides of the silicon wafer by low-pressure chemical vapor deposition (LPCVD), as shown in Figure 3(b). The silicon nitride layer obstructs the thermal conduction to the silicon substrate and enhances the heat absorption in the pyroelectric layers. The bottom electrode was deposited on the substrates by electron beam evaporation and patterned by the shadow mask method, as shown in 
Figure 3(c). The bottom electrode was composed of gold and chromium. The latter was an adhesion layer to promote the adhesion between the gold electrode and the substrate. The thickness of the gold and chromium was $50 \mathrm{~nm}$ and $5 \mathrm{~nm}$, respectively. The next step was to deposit $\mathrm{ZnO}$ films with a thickness of $1 \mu \mathrm{m}$ by $\mathrm{AD}$ and pattern by a shadow mask to expose the bottom electrode, as shown in Figure 3(d). Then, $\mathrm{ZnO}$ film with a thickness of $2 \mu \mathrm{m}$ was deposited on the preceding $\mathrm{ZnO}$ film and patterned by a shadow mask with a comb-like form, as shown in Figure 3(e). These ZnO films promoted by laser annealing ensued, as shown in Figure 3(f). The processing step in Figure 3(g) was used to deposit the top electrode on the $\mathrm{ZnO}$ layer. The composition and deposition of the top electrode were similar to those of the bottom electrode. The top electrode was also patterned by the shadow mask with a comb-like form. The shadow mask method simplified the processing steps, shortened the processing time and further avoided chemical corrosion to the $\mathrm{ZnO}$ films during the photolithography process.

\subsection{Signal Measurement}

A response measurement system (Figure 4) was used to determine the output signals of the present $\mathrm{ZnO}$ pyroelectric devices. The radiation source was a calibrated infrared (IR) laser of $900 \mathrm{~nm}$ wavelength and $7 \mathrm{~mW}$ maximum power. The laser beam was chopped and molded as a square wave with a modulated frequency $(\omega)$ by a programmable function generator. A prism was used to split the modulated beam into two beams. The two beams had the same power: one was reflected on a photodiode as the reference signal, and the other was expanded via a beam expander, such that the beam spot covered the entire region of the patterned top electrode of the $\mathrm{ZnO}$ pyroelectric sensors. A reference signal produced by the photodiode was compared with the output signals generated by the present sensors on the oscilloscope. The output voltage of the sensor was treated using an SR560 low-noise voltage amplifier. Finally, a digital oscilloscope was used to record and display both the output signals of the sensors and the photodiode.

Figure 4. Schematic diagram of responsivity measurement system.

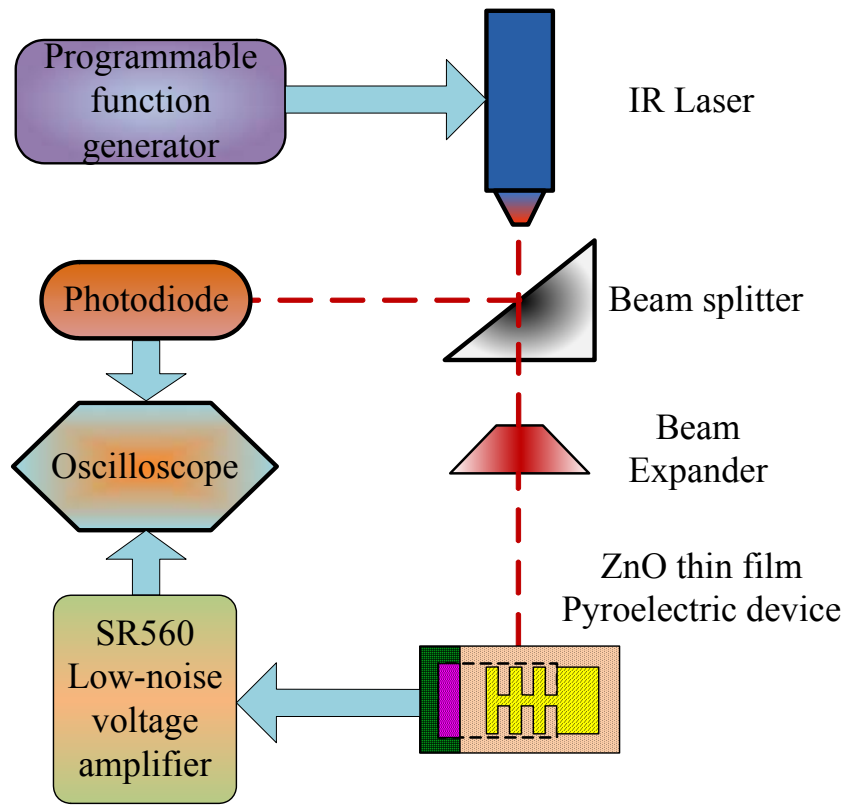




\section{Results and Discussion}

$\mathrm{AD}$ is a form of gas deposition method or jet printing method without vaporization of the material, which is a novel and very attractive coating method for ceramic integration. A high deposition rate and a low deposition temperature are the main advantages for $\mathrm{AD}$, which can accelerate the fabrication of films applied on microdevices, sensors or actuators. AD is an excellent candidate for fabricating low cost and highly reliable embedded electric devices in printed circuit boards. Figure 5 shows the XRD patterns for the $\mathrm{ZnO}$ films with as-grown and laser annealing.

Figure 5. XRD patterns of the $\mathrm{ZnO}$ films with as-grown and laser annealing.

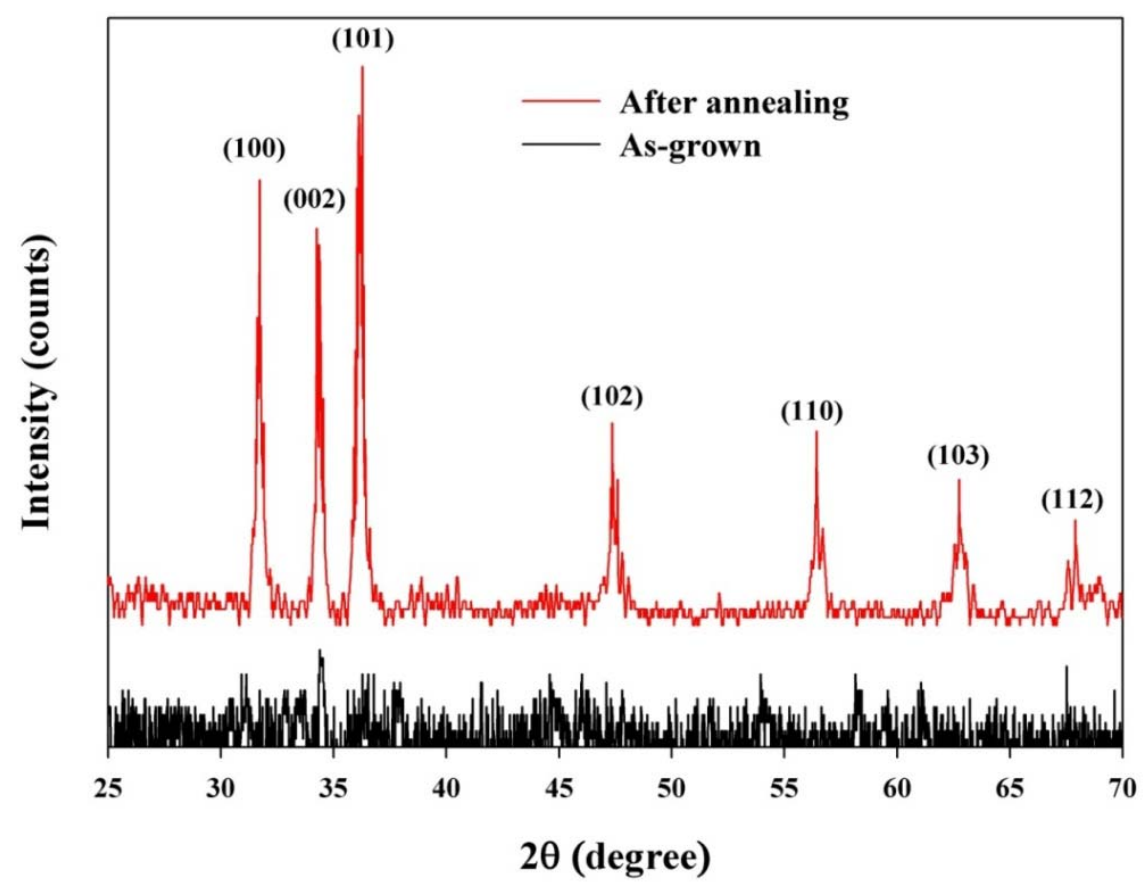

The laser-irradiated $\mathrm{ZnO}$ film exhibited a hexagonal wurtzite phase consistent with crystalline materials. Figure 6 shows the SEM micrographs for the $\mathrm{ZnO}$ films with as-grown and laser annealing. The as-grown $\mathrm{ZnO}$ films were observed to have sheet-like grains, which were consistent with the starting particles of the $\mathrm{ZnO}$ powder. Laser annealing is a rapid and local heating and cooling process, which can also result in a post-growth of grains, causing more grains to migrate and coalesce [20]. Laser irradiation results in the development of lateral facets and the migration of the $\mathrm{ZnO}$ grains, as well as the production of the large punctures between the grains, which can be more effective for relaxing the residual compressive stress in the as-grown $\mathrm{ZnO}$ films [20]. Although the $\mathrm{ZnO}$ films with laser annealing appear to have a porous structure, their application in pyroelectric devices is beneficial as porous $\mathrm{ZnO}$ film increases the absorption of heat radiation. Moreover, annealing in a nitrogen atmosphere suppresses the re-evaporation of oxygen and, hence, the non-radiative defects. Therefore, the properties of $\mathrm{ZnO}$ films are improved by annealing and the density of defects in $\mathrm{ZnO}$ films is decreased [21]. 
Figure 6. SEM micrographs of the ZnO films: (a) as-grown and (b) after laser annealing.

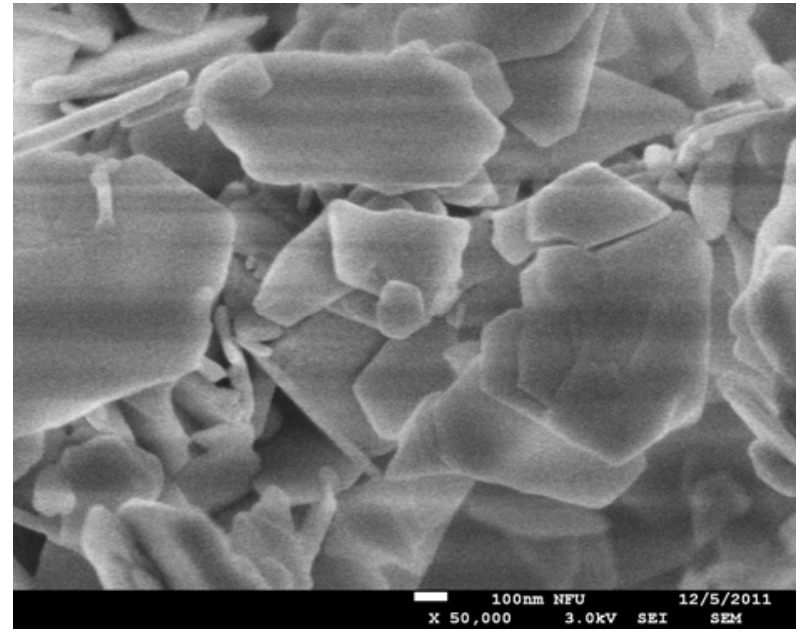

(a)

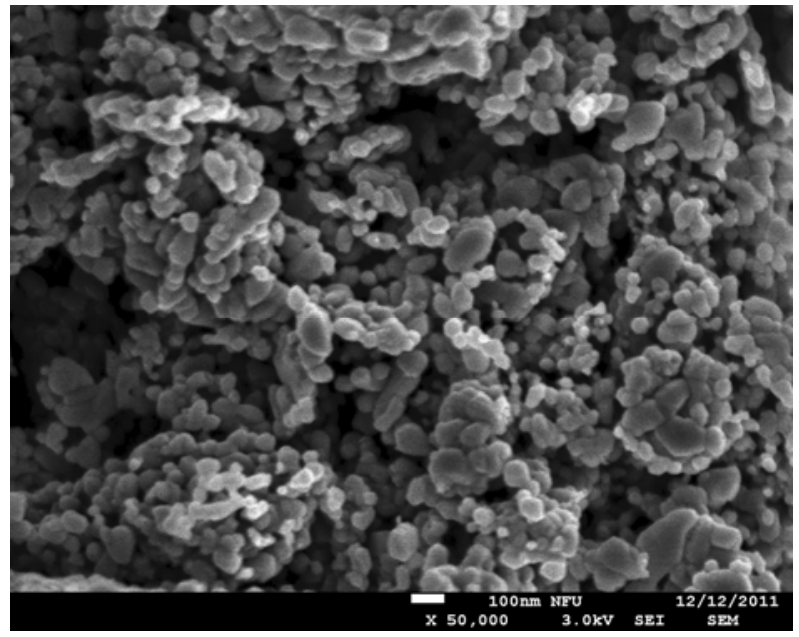

(b)

A three-dimensional pattern has been presented and etched on the responsive element of $\mathrm{LiTaO}_{3}$ by using lateral temperature gradients produced on the sidewalls of the responsive element to enhance the pyroelectric response [7]. In the present study, a two-dimensional finite element model was generated by the commercial multi-physics software COMSOL MULTIPHYSICS ${ }^{\circledR} 3.5$ to explore the temperature variation rate in $\mathrm{ZnO}$ pyroelectric devices with both comb-like and fully covered electrodes. Material parameters of the $\mathrm{ZnO}$ film, the substrate and electrodes are listed in Table 4.

Table 4. Material parameters used for finite element analysis.

\begin{tabular}{lcccc}
\hline \multicolumn{1}{c}{ Material } & $\begin{array}{c}\text { Thermal } \\
\text { conductivity } \\
\left(\mathbf{W m} \mathbf{m}^{-\mathbf{1}} \cdot \mathbf{K}^{-\mathbf{1}}\right)\end{array}$ & $\begin{array}{c}\text { Specific heat } \\
\left(\mathbf{J g}^{-\mathbf{1}} \cdot \mathbf{K}^{-\mathbf{1}}\right)\end{array}$ & $\begin{array}{c}\text { Density } \\
\left(\mathbf{g} \cdot \mathbf{c m}^{-3}\right)\end{array}$ & $\begin{array}{c}\text { Thickness } \\
(\boldsymbol{\mu m})\end{array}$ \\
\hline Silicon substrate & 163 & 0.703 & 2.330 & 5 \\
Silicon nitride & 20 & 0.700 & 3.100 & 1 \\
Top and bottom electrodes & 317 & 0.129 & 19.300 & 0.1 \\
Zinc oxide & 6 & 0.125 & 5.676 & 3 \\
\hline
\end{tabular}

All parameters were assumed to be isotropic. The models were meshed by regular mesh, as shown in Figure 7. Fitting the structure of patterned devices, $\mathrm{W}_{\mathrm{t}}$ is defined as the electrode width and set at $500 \mu \mathrm{m} . \mathrm{H}_{\mathrm{t}}$ is defined as the trench depth and set at $2 \mu \mathrm{m}$. The incident irradiation power applied to the top side of the $\mathrm{ZnO}$ pyroelectric devices was approximately $1.228 \times 10^{-12} \mathrm{~W} / \mu \mathrm{m}^{2}$ [22]. Although the vertical sidewalls of the trenches had a high potential to absorb the incidental irradiation power, there was no irradiation power applied to make a worst-case scenario for probing the temperature fields and predicting the efficiency of $\mathrm{ZnO}$ pyroelectric devices. Moreover, thermal isolation was applied to the rear side of the $\mathrm{ZnO}$ pyroelectric devices, and the two lateral sides were symmetric in order to serve as boundary conditions. 
Figure 7. Finite element model for the $\mathrm{ZnO}$ pyroelectric devices: (a) fully covered electrode; (b) comb-like electrode.

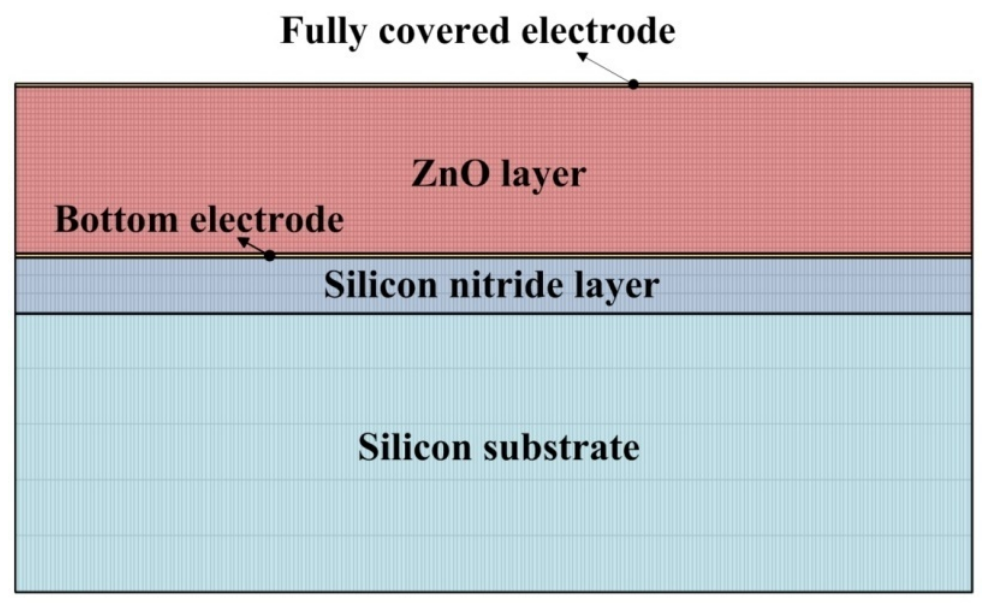

(a)

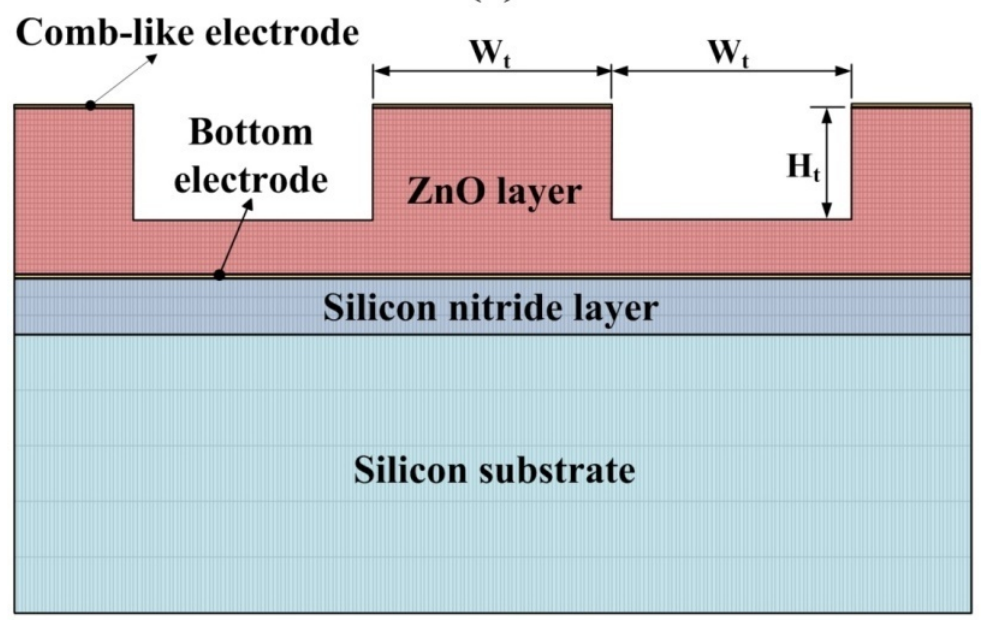

(b)

Figure 8(a) shows the transient temperature variation field at the time of the maximum peak at the bottom point of the $\mathrm{ZnO}$ film when the fully covered electrode was used to fabricate the $\mathrm{ZnO}$ pyroelectric devices. The temperature variation rate in the $\mathrm{ZnO}$ film increased gradually toward the top electrode as a result of the incidental radiation power applied to the top electrode. Figure 8(b) shows the transient temperature variation field at the time of the maximum peak at the bottom point of the $\mathrm{ZnO}$ film when the comb-like electrode with an electrode width of $500 \mu \mathrm{m}$ and a trench depth of $2 \mu \mathrm{m}$ was used to fabricate the $\mathrm{ZnO}$ pyroelectric devices. Because the incidental radiation power was applied on the top side of the $\mathrm{ZnO}$ pyroelectric devices, the temperature variation rates at the top side of the $\mathrm{ZnO}$ film under both the comb-like and the fully covered electrodes were no different. Obviously, the temperature variation rate at the bottom side of the $\mathrm{ZnO}$ film was improved about $32 \%$ by lateral temperature gradients. The three-dimensional $\mathrm{ZnO}$ film could bring lateral temperature gradients on the sidewalls of the $\mathrm{ZnO}$ layer and so increase the temperature variation rate of the responsive element. 
Figure 8. Transient temperature variation field in the $\mathrm{ZnO}$ pyroelectric sensors: (a) fully covered electrode; (b) comb-like electrode.

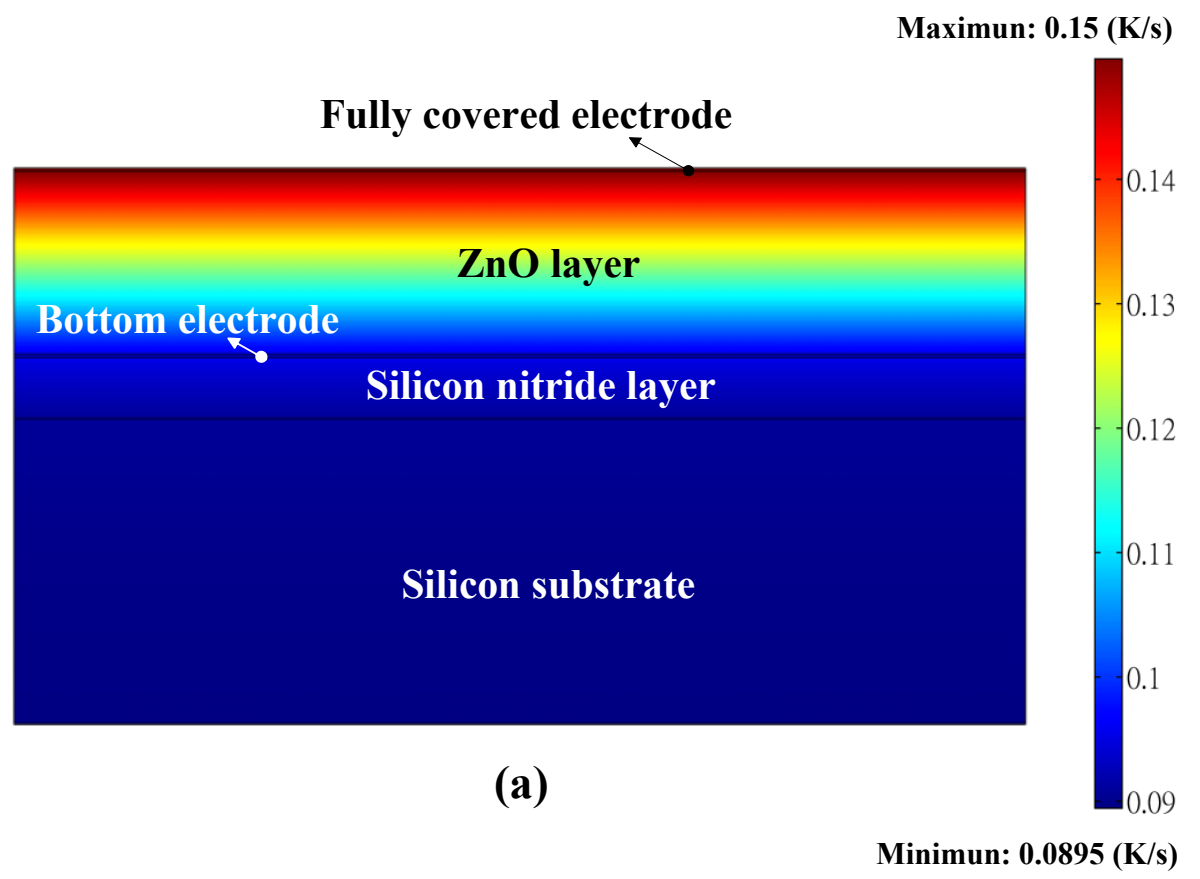

Maximun: $1.19(\mathrm{~K} / \mathrm{s})$

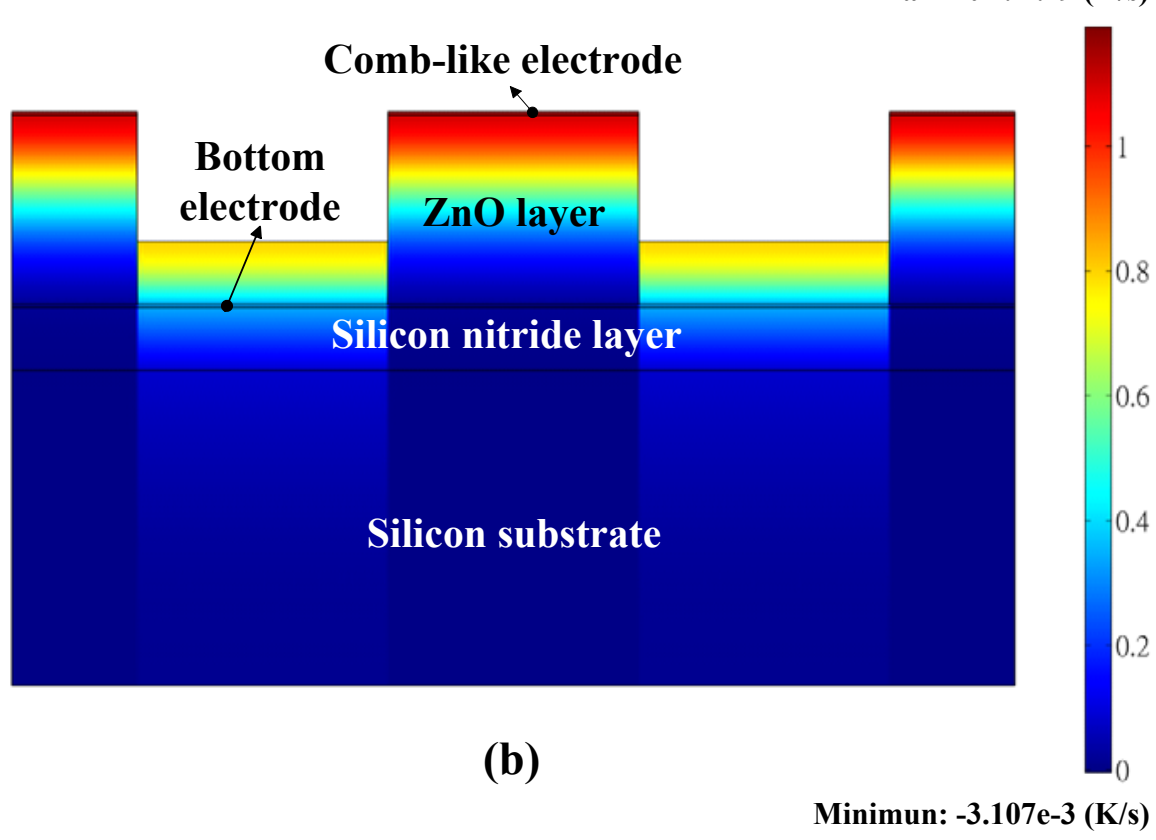

When $\mathrm{ZnO}$ is subjected to temperature variation, its internal polarization produces an electrical field that induces a voltage response between the top and bottom electrodes. The response is proportional to the temperature variation rate in the $\mathrm{ZnO}$ layer, as no temperature variation in the $\mathrm{ZnO}$ layer results in no internal polarization change and, thus, no response voltage. Therefore, the IR laser beam was chopped and molded as a square wave with a modulated frequency to obtain a temperature variation in the $\mathrm{ZnO}$ layer by a programmable function generator. In the present study, the AD method was used to fabricate a multilayer $\mathrm{ZnO}$ pyroelectric device with a comb-like top electrode and three-dimensional 
$\mathrm{ZnO}$ film, as compared to a fully covered top electrode and a single $\mathrm{ZnO}$ layer. The top electrode area of the fully covered type was about $14.4 \mathrm{~mm}^{2}$, which was larger than that of the comb-like top electrode at about $10.6 \mathrm{~mm}^{2}$. The single $\mathrm{ZnO}$ layer possessed a thickness of $3 \mu \mathrm{m}$, which was the same as the three-dimensional $\mathrm{ZnO}$ film. The fabricated $\mathrm{ZnO}$ pyroelectric device with the fully covered electrode and the single $\mathrm{ZnO}$ layer, compared to that with the comb-like electrode and three-dimensional $\mathrm{ZnO}$ film, fabricated through $\mathrm{ZnO}$ film deposited by $\mathrm{AD}$, are shown in Figure 9.

Figure 9. Fabricated $\mathrm{ZnO}$ pyroelectric devices: (a) the fully covered electrode with the single $\mathrm{ZnO}$ layer; (b) the comb-like electrode with the three-dimensional $\mathrm{ZnO}$ film; (c) the patterned device before top electrode deposited.

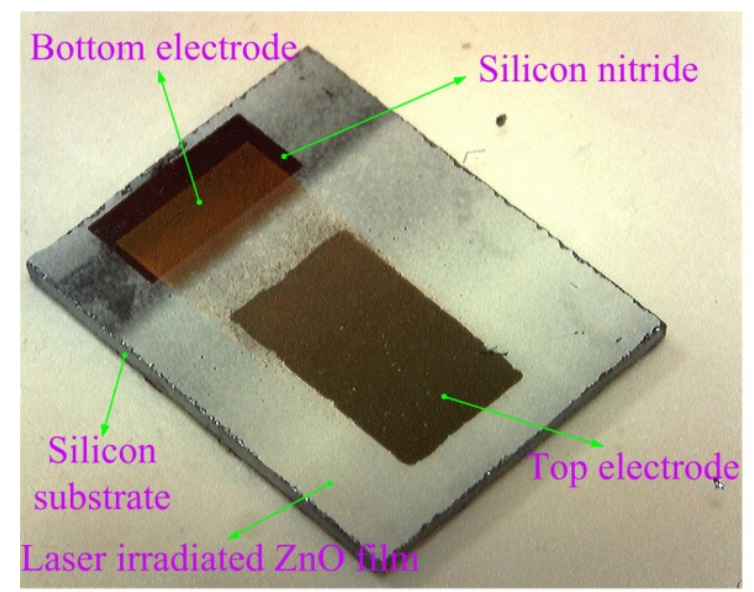

(a)

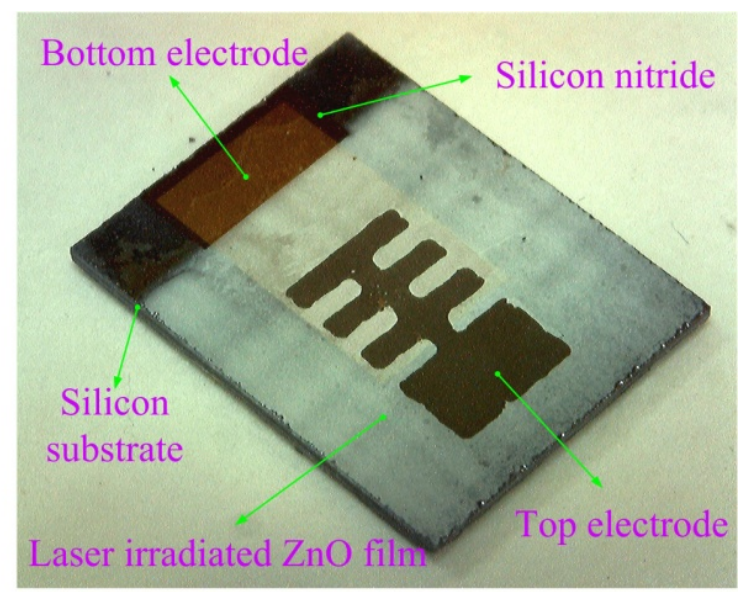

(b)

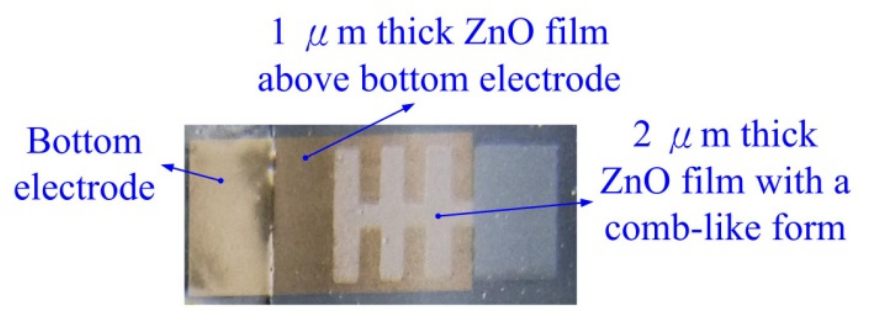

(c)

Figure 10 shows the waveform of the voltage response of the present $\mathrm{ZnO}$ pyroelectric device compared with that of the reference signal of the photodiode on the oscilloscope. The signal of the fabricated $\mathrm{ZnO}$ pyroelectric device presented a harmony with the reference signal of the photodiode. Because pyroelectric devices start applying the temperature variation rate, the waveform of the voltage response rapidly rises to a maximum value and then slowly decreases due to the sustained radiation source applied. Therefore, increasing the heat absorption of porous film is helpful in enhancing the voltage response of pyroelectric devices.

Figure 11 shows the voltage response $(R v)$ of the present $\mathrm{ZnO}$ pyroelectric devices with $\mathrm{ZnO}$ film deposited by $\mathrm{AD}$ and ameliorated by laser annealing. 
Figure 10. Voltage responsivity waveform of the present $\mathrm{ZnO}$ pyroelectric devices, compared to that of the reference signal of the photodiode on the oscilloscope.

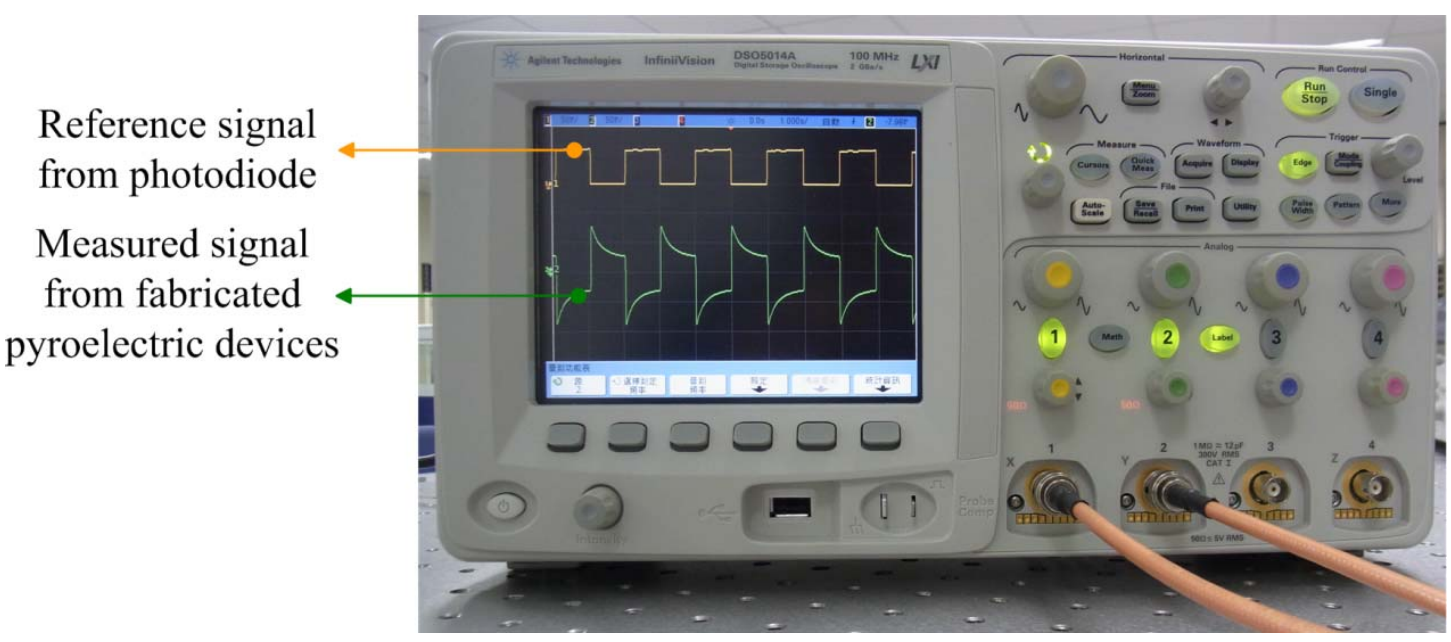

Figure 11. Voltage responsivity of the fabricated $\mathrm{ZnO}$ pyroelectric sensors with the comb-like electrode, compared to the fully covered electrode.

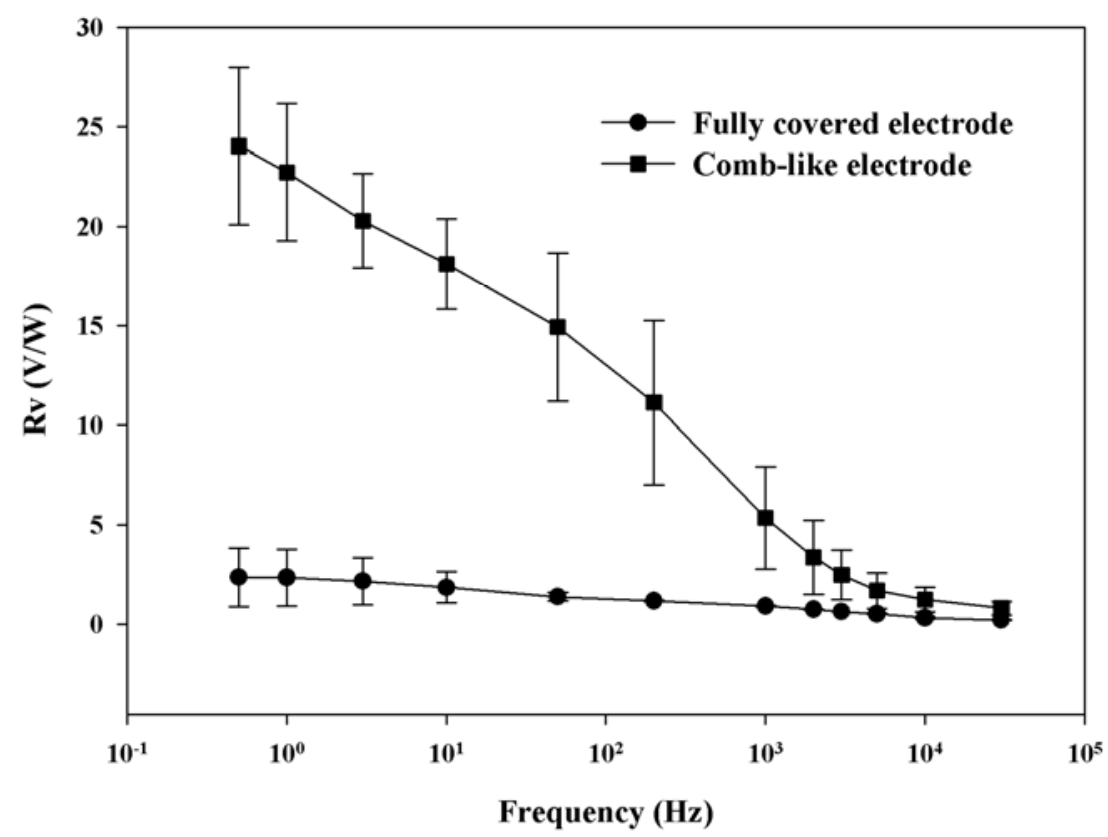

There were six samples for each electrode layout. $R v$ is defined as the ratio of the output voltage of the device to the input power of the incident heat source. The voltage response of the pyroelectric sensor was as expected, in that it decreased as the modulated frequency increased. Moreover, as the frequency went beyond $1,000 \mathrm{~Hz}$, the voltage response seriously decreased with increasing modulated frequency. This was due to the fact that the response time of the sensor could not catch the variation speed of the incident heat source. Moreover, the voltage response still had a good performance at the period of $33 \mu \mathrm{s}$. The $\mathrm{ZnO}$ pyroelectric device with the comb-like electrode possessed a voltage response about 9 times greater than that with the fully covered electrode at a low frequency. At a high frequency of about $3,000 \mathrm{~Hz}(33 \mu \mathrm{s})$, the $\mathrm{ZnO}$ pyroelectric device with the comb-like electrode possessed a voltage response about four times greater than that with the fully covered electrode. 
Although the fully covered electrode possessed a larger electrode area than the comb-like electrode, the radiation absorption of the $\mathrm{ZnO}$ layer was seriously obstructed by the fully covered top electrode. Therefore, increasing only the top electrode area without consideration of the electrode layout and three-dimensional $\mathrm{ZnO}$ film could not effectively improve the response of pyroelectric devices. Hence, $\mathrm{AD}$ did indeed accelerate the deposition process of $\mathrm{ZnO}$ films for applications in pyroelectric devices, as well as reduce the manufacturing cost for the fabrication of microdevices. Moreover, the porous $\mathrm{ZnO}$ films with the three-dimensional pattern fabricated by $\mathrm{AD}$ and integrated with the comb-like top electrode improved the voltage response of pyroelectric devices.

\section{Conclusions}

In this study, $\mathrm{AD}$ was successfully used to accelerate the application of $\mathrm{ZnO}$ films in pyroelectric devices. A three-dimensional $\mathrm{ZnO}$ film fabricated by $\mathrm{AD}$ with the shadow mask method, integrated with a comb-like top electrode, enhanced the voltage response of $\mathrm{ZnO}$ pyroelectric devices. At a high frequency of about $3,000 \mathrm{~Hz}(33 \mu \mathrm{s})$, the $\mathrm{ZnO}$ pyroelectric device with the comb-like electrode possessed a voltage response about four times greater than that with the fully covered electrode. The three-dimensional $\mathrm{ZnO}$ film did indeed induce lateral temperature gradients on the sidewalls of the $\mathrm{ZnO}$ layer, thereby increasing the temperature variation rate of the responsive element, enhancing the voltage response and reducing the response time of $\mathrm{ZnO}$ pyroelectric devices.

\section{Acknowledgments}

The authors are thankful for the financial support from the National Science Council of Taiwan through Grant No. NSC 100-2221-E-150-048, and the experimental support from the Common Laboratory for Micro and Nano Science and Technology at the National Formosa University. The contributions of Pei-Zen Chang and Xuan-Yu Wang to the technique support are particularly acknowledged.

\section{References}

1. Winfield, R.J.; Koh, L.H.K.; O’Brien, S.; Crean, G.M. Excimer laser processing of ZnO thin films prepared by the sol-gel process. Appl. Surf. Sci. 2007, 254, 855-858.

2. Amézaga-Madrid, P.; Antúnez-Flores, W.; Ledezma-Sillas, J.E.; Murillo-Ramírez, J.G.; Solís-Canto, O.; Vega-Becerra, O.E.; Martínez-Sánchez, R.; Miki-Yoshida, M. Synthesis microstructural characterization and optical properties of undoped, $\mathrm{V}$ and $\mathrm{Sc}$ doped $\mathrm{ZnO}$ thin films. J. Alloy Compd. 2011, 509, S490-S495.

3. Kim, J.J.; Bak, J.Y.; Lee, J.H.; Kim, H.S.; Jang, N.W.; Yun, Y.; Lee, W.J. Characteristics of laser-annealed $\mathrm{ZnO}$ thin film transistors. Thin Solid Films 2010, 518, 3022-3025.

4. Wei, C.S.; Lin, Y.Y.; Hu, Y.C.; Wu, C.W.; Shih, C.K.; Huang, C.T.; Chang, S.H. Partial-electroded $\mathrm{ZnO}$ pyroelectric sensors for response improvement. Sens. Actuators A 2006, 128, 18-24.

5. Hsiao, C.C.; Huang, K.Y.; Hu, Y.C. Fabrication of a ZnO pyroelectric. Sensors 2008, 8, 185-192.

6. Park, S.H.; Seo, B.C.; Park, H.D.; Yoon, G. Film bulk acoustic resonator fabrication for radio frequency filter applications. Jpn. J. Appl. Phys. 2000, 39, 4115-4119. 
7. Norkus, V.; Schulze, A.; Querner, Y.; Gerlach, G. Thermal effects to enhance the response of pyroelectric infrared detectors. Proced. Eng. 2010, 5, 944-947.

8. Lee, F.Y.; Navid, A.; Pilon, L. Pyroelectric waste heat energy harvesting using heat conduction. Appl. Therm. Eng. 2012, 37, 30-37.

9. Cuadras, A.; Gasulla, M.; Ferrari, V. Thermal energy harvesting through pyroelectricity. Sens. Actuators A 2010, 158, 132-139.

10. Nguyen, H.; Navid, A.; Pilon, L. Pyroelectric energy converter using co-polymer P(VDF-TrFE) and Olsen cycle for waste heat energy harvesting. Appl. Therm. Eng. 2010, 30, 2127-2137.

11. Sebald, G.; Lefeuvre, E.; Guyornar, D. Pyroelectric energy conversion: Optimization principles. IEEE Trans. Ultrason. Ferroelect. Freq. Control 2008, 55, 538-551.

12. Hsiao, C.C.; Ciou, J.C.; Siao, A.S.; Lee, C.Y. Temperature field analysis for PZT pyroelectric cells for thermal energy harvesting. Sensors 2011, 11, 10458-10473.

13. Hsiao, C.C.; Siao, A.S.; Ciou, J.C. Improvement of pyroelectric cells for thermal energy harvesting. Sensors 2012, 12, 534-548.

14. Akedo, J. Aerosol deposition of ceramic thick films at room temperature: Densification mechanism of ceramic layers. J. Am. Ceram. Soc. 2006, 89, 1834-1839.

15. Akedo, J.; Ichiki, M.; Kikuchi, K.; Maeda, R. Jet molding system for realization of three-dimensional micro-structures. Sens. Actuators A 1998, 69, 106-112.

16. Wang, X.Y.; Lee, C.Y.; Hu, Y.C.; Shih, W.P.; Lee, C.C.; Huang, J.T.; Chang, P.Z. The fabrication of silicon-based PZT microstructures using aerosol deposition method. J. Micromech. Microeng. 2008, 18, doi:10.1088/0960-1317/18/5/055034.

17. Miyoshi, T. Preparation of full-dense $\mathrm{Pb}(\mathrm{Zr}, \mathrm{Ti}) \mathrm{O}_{3}$ ceramics by aerosol deposition. J. Am. Ceram. Soc. 2008, 91, 2098-2104.

18. Kim, C.R.; Lee, J.Y.; Shin, C.M.; Leem, J.Y.; Ryu, H.; Chang, J.H.; Lee, H.C.; Son, C.S.; Lee, W.J.; Jung, W.G.; et al. Effects of annealing temperature of buffer layer on structural and optical properties of $\mathrm{ZnO}$ thin film grown by atomic layer deposition. Solid State Commun. 2008, 148, 395-398.

19. Kim, C.R.; Shin, C.M.; Lee, J.Y.; Heo, J.H.; Lee, T.M.; Park, J.H.; Ryu, H.; Son, C.S.; Chang, J.H. Influence of annealing duration on optical property and surface morphology of $\mathrm{ZnO}$ thin film grown by atomic layer deposition. Curr. Appl. Phys. 2010, 10, S294-S297.

20. Lu, H.; Tu, Y.; Lin, X.; Fang, B.; Luo, D.; Laaksonen, A. Effects of laser irradiation on the structure and optical properties of $\mathrm{ZnO}$ thin films. Mater. Lett. 2010, 64, 2072-2075.

21. Quang, L.H.; Chua, S.J.; Loh, K.P.; Fitzgerald, E. The effect of post-annealing treatment on photoluminescence of $\mathrm{ZnO}$ nanorods prepared by hydrothermal synthesis. J. Cryst. Growth 2006 287, 157-161.

22. Li, L.; Zhang, L.; Yao, X.; Li, B. Computer simulation of temperature field of multilayer pyroelectric thin film IR detector. Ceram. Int. 2004, 30, 1847-1850.

(C) 2012 by the authors; licensee MDPI, Basel, Switzerland. This article is an open access article distributed under the terms and conditions of the Creative Commons Attribution license (http://creativecommons.org/licenses/by/3.0/). 